\title{
Comprehensive review of the Universal Immunization Programme (UIP) - Identifying gaps and assist in formulating improvement plan for routine immunization in few states of India
}

\author{
Vandana Gurnani $^{\mathrm{b}}$, Pritu Dhalaria ${ }^{\mathrm{a}, *}$, Pradeep Haldar ${ }^{\mathrm{b}}$, Mahesh Kumar Aggarwal ${ }^{\mathrm{b}}$, \\ Prem Singh $^{a}$, Ayushi Agarwal ${ }^{a}$, Apurva Rastogi ${ }^{a}$, Amrita Kumari ${ }^{a}$, Gopal Krishna Soni ${ }^{a}$ \\ ${ }^{a}$ Immunization Technical Support Unit, Ministry of Health \& Family Welfare, Government of India, New Delhi, India \\ ${ }^{\mathrm{b}}$ Ministry of Health \& Family Welfare, Government of India, New Delhi, India
}

\section{A R T I C L E I N F O}

\section{Keywords:}

Comprehensive review

Universal immunization programme

Program implementation

Thematic area

Mechanism

Immunization coverage improvement plan (ICIP)

\begin{abstract}
A B S T R A C T
Introduction: Despite the concerted efforts of the central and state governments and other immunization stakeholders, full immunization rates in India remains low. This paper outlines the findings of a comprehensive review of the Universal Immunization Programme (UIP) and provide recommendations to formulate an action plan for improving routine immunization coverage.

Design: A mixed-method approach was adopted to collect data under four thematic areas, namely programme implementation, vaccine logistics and cold chain, data recording and reporting system, and programme communication in five high priority states. Results obtained for indicators under each thematic area, were then divided into four categories: a) $\geq 90 \%$ - good, b) 70-90\%-fair, c) 50-70 \% - average and d) < $50 \%$ - poor. Setting: The review was undertaken in five high-priority states - Bihar, Madhya Pradesh, Maharashtra, Rajasthan and Uttar Pradesh. Four districts were selected base on a scoring criterion from each state.

Results: The programme implementation was found average ranging from $53.6 \%$ to $63.8 \%$ and the mechanism of vaccine logistic and cold chain was fair ranging from $71.0 \%$ to $79.4 \%$ across all the states. The mechanism of data recording and reporting was poor in Madhya Pradesh (36.8 \%) and Maharashtra (47.0 \%) and average in the remaining three states. Programme communication needs considerable improvement. Except Madhya Pradesh $(62.4 \%)$, the communication activities were poor in the other four states.

Conclusion: The methodology of the review will help in identifying critical gaps and strengths in the immunization processes and in formulating an immunization coverage improvement plan (ICIP) in the states.
\end{abstract}

\section{Introduction}

The expanded program on immunization was introduced in 1978 , followed by the Universal Immunization Program (UIP) in 1985. The program has contributed significantly to ensure equity to children accessing the public health system and it is one of the largest in the world. ${ }^{1}$ The WHO defined the immunization session, effective only if each child and women attending it receives all vaccines according to their eligibility, by following necessary safety and efficacy procedures and returns timely for the next time. ${ }^{2}$ India's immunization program is the largest public health program in the world, catering to an annual cohort of $\sim 2.6$ crore infants and 3 crore pregnant women, through 90 lakh sessions every year. ${ }^{3}$ Despite the strenuous efforts to improve child health, Infant Mortality Rate (IMR) of India is 33 and the under-five mortality rate (U5MR) is 37 per 1000 live births. ${ }^{4}$ A growing number of studies in India examined inequalities in child health status including full immunization coverage. ${ }^{5}$ Socioeconomic inequalities in child health and performance of immunization programme are a major concern to achieve the Sustainable Development Goal by 2030. The data of NFHS-4 shows currently India has a gap of $38 \%$ from achieving the goal of universal immunization coverage of $90 \%{ }^{6}$ Over the last two and half decades, immunization coverage among children aged $12-23$ months in

\footnotetext{
* Corresponding author.

E-mail addresses: vandana.g@ias.nic.in (V. Gurnani), pritudhalaria@in.jsi.com (P. Dhalaria), pradeephaldar@yahoo.co.in (P. Haldar), mkagarwal2@gmail.com

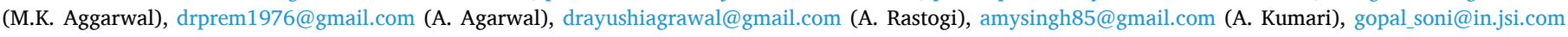
(G.K. Soni).
} 
the country has increased at a very slow pace of around $1 \%$ each year (from $35 \%$ in $1992-93$ to $62 \%$ in $2015-16$ ). ${ }^{7}$ As per NFHS-4 compare to the rest of India the full immunization coverage (FIC) is very poor in empowered action group (EAG) states which constitutes more than $40 \%$ of the total population of India and data on immunization and related indicators for the EAG states highlights interstate and intrastate disparities. ${ }^{7}$

NFHS-4 also highlights that there is still a significant inequality in full immunization coverage across states of India, ranging from $91 \%$ in Puducherry to $35 \%$ in Nagaland. Yet, despite the concerted efforts of the central and state governments and other immunization stakeholders, full immunization rates in India remains low. Due to the observed slow improvement rate, India is making efforts by designing various strategies such as special immunization campaigns like Mission Indradhanush (MI). The campaign was launched in December 2014 to reach out the unvaccinated and partially vaccinated children through focus on hardto-reach and high-risk areas. ${ }^{8}$ First two phases of MI contributed to an increase in FIC by $6.7 \%$ points according to the Integrated Child Health \& Immunization Survey (INCHIS). ${ }^{9}$ Intensified Mission Indradhanush (IMI) was launched in October 2017 to accelerate vaccination coverage. ${ }^{10}$ Four rounds of IMI were conducted between October 2017 and January 2018 in the identified geographic areas. ${ }^{11}$ Regardless of these efforts, an issue of inequity is observed at different platforms. Hence, it becomes pertinent for the states to identify bottlenecks and gaps that are likely to delay the achievement of $90 \%$ FIC.

Different fragmented assessments and reviews have been carried out by different agencies for example, Acute Flaccid Paralysis (AFP) surveillance cum UIP review, Data Quality Assessment (DQA) and Electronic Vaccine Management (EVM) assessment. There is a growing need to integrate different assessments in the form of comprehensive review for UIP. With the learnings of previous reviews, to assess reasons for inequities within the state and to accelerate the efforts to reach the goal, a comprehensive UIP review was planned in identified five high-priority states by the Ministry of Health and Family Welfare (MoHFW). The Immunization Technical Support Unit (ITSU) under guidance of MoHFW developed a review mechanism by amalgamating all the critical thematic areas of supply and demand side. Subsequently, this will enable the states to develop state-specific immunization coverage improvement plans, which can be used as a tracking tool for measuring progress on various components of UIP.

\section{Method}

Study area and design: Five high priority states which contribute maximum number of target population were identified for review across India in consultation with the MoHFW. Each state was further divided into two zones (Eastern Zone \& Western Zone) considering geographic and demographic characteristics (Figure-1). For selection of review districts, they were given scores based on the following indicators from National Family Health Survey-4 data:

1. Percentage of full immunization coverage (FIC)

2. Percentage of drop out for BCG - DPT3

3. Percentage of institutional deliveries

Table 1

Indicators and specific scores.

\begin{tabular}{llll}
\hline $\begin{array}{l}\text { Indicators } \\
\begin{array}{l}\text { Full immunization } \\
\text { coverage (FIC) }\end{array}\end{array}$ & $\begin{array}{l}\text { BCG - DPT 3 } \\
\text { Drop Out }\end{array}$ & $\begin{array}{l}\text { Institutional } \\
\text { deliveries }\end{array}$ & $\begin{array}{l}\text { Score } \\
\text { allocated }\end{array}$ \\
\hline$\geq 90 \%$ & $<10 \%$ & $\geq 90 \%$ & 1 \\
$75-90 \%$ & $10-20 \%$ & $80-90 \%$ & 2 \\
$60-75 \%$ & $20-30 \%$ & $70-80 \%$ & 3 \\
$45-60 \%$ & $30-40 \%$ & $60-70 \%$ & 4 \\
$<45 \%$ & $\geq 40 \%$ & $<60 \%$ & 5 \\
\hline
\end{tabular}

Each indicator was given a value ranging from 1 to 5 as given in Table 1 . The scoring was designed such that a higher score represents poor performance. Total score for each district was calculated by adding the values for each of the three indicators.

Fig. 1: A good performing and a poor performing district were selected from each of the two zones based on aggregate scores. If more than one district scored the same, then the district was selected randomly. From each of the selected districts, one good performing and one poor performing block was selected on the basis of FIC (HMIS data). Sub-centers in the selected blocks were chosen randomly. The state capital and district headquarters (HQ) were selected to assess urban immunization.

Data type: Both primary and secondary data were used in this review. Primary data was collected from the selected districts under the four thematic areas for all the identified indicators as highlighted in Table 2. A total of 30 indicators (as illustrated in Table 2) were assessed under these thematic areas. Qualitative data was collected for "programme communication" component where semi-structured questionnaires were used for interviewing key respondents. Under urban immunization, ten indicators were assessed. Secondary data was recorded under selected indicators like human resource and accountability and governance. Additionally, an excel tool adapted from WHO methodology was used for data quality assessment.

Duration and process of review: The review was conducted for five days in each state and district level, followed by a debriefing on key findings to the state and respective district officials. The review was conducted between April 2018 to September 2018. A team encompassing of experts visited each state for an intensive five-day exercise. Teams of six members each, comprising of domain experts, were responsible for data collection from each of the identified four districts and state level as well. State participation was also ensured during the process to help in capacity building of officials, so that they can conduct self-assessment of the immunization processes in the future. At each step of preparation for the review, Immunization division and experts from CORE, GHS, JSI, NCCVMRC, NHSRC, NIHFW, UNDP, UNICEF and WHO were engaged to give inputs through multiple meetings and communications.

Data entry: The widely used mobile based data collection application Open Data Kit is used for the data collection. The questionnaires were designed on an android based Open Data Kit tool. ${ }^{12}$ A set of indicators were finalized for analysis, based on the requirement and scope of the review.

Indicators: The assessed indicators under each thematic area are elaborated in the below table:

Data Analysis: An excel based calculation worksheet was prepared for the agreed indicators for analysis, and a comparative analysis across relevant indicators was done for each district. Each question under a particular indicator was scored. Hence, a cumulative score was obtained for each indicator which was then translated into percentages. These results were then divided into four categories: a) $\geq 90 \%$ - good; b) 70-90\%-fair, c) 50-70\% - average d) $<50 \%$ - poor.

\section{Results}

Under the program implementation domain, the governance and accountability were found average for Madhya Pradesh (63.0\%), Maharashtra (57.0 \%), Rajasthan (54.0 \%) and Uttar Pradesh (57.0 \%). The governance and accountability for Bihar was fair $(79.0 \%)$. The human resource and infrastructure status were found to be fair for all the other states except Bihar (61.0\%). Poor training status was observed in Madhya Pradesh (35.0 \%) and Uttar Pradesh (43.0 \%). Availability of Microplanning was average in Bihar (56.0\%), Maharashtra (57.0\%) and Uttar Pradesh (52.0 \%). In Madhya Pradesh (42.0 \%) and Rajasthan (36.0\%), poor microplanning was observed. Session site observation was average for the four states except Uttar Pradesh (48.0\%). The Adverse Event Following Immunization (AEFI) reporting status was 


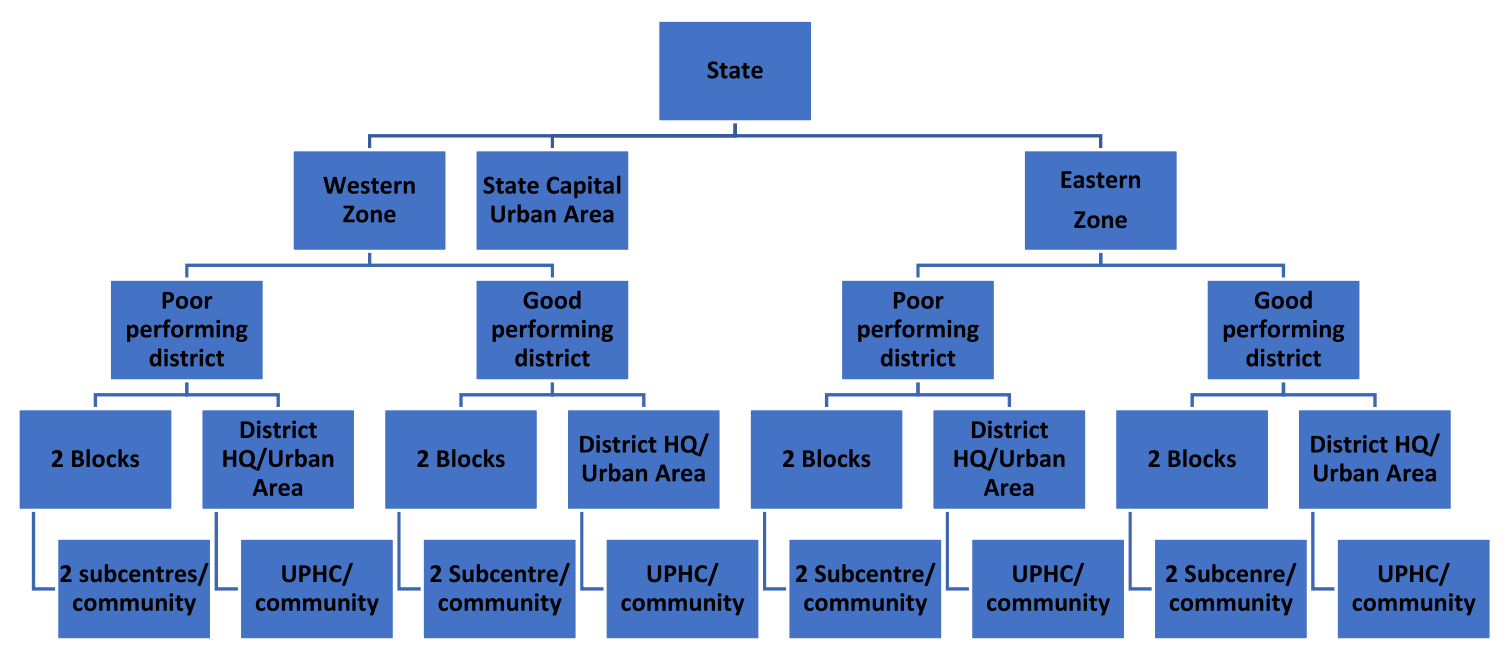

Fig. 1. Review area selection mechanism.

poor for Madhya Pradesh (45.0 \%) and Rajasthan (28.0 \%), whereas VPD knowledge and reporting among ANMs was found to be poor across all the states (Table 3).

In the vaccine, logistics and cold chain domain, human resource and training on cold chain was observed fair in Bihar, Madhya Pradesh, Maharashtra and Rajasthan. For Uttar Pradesh, it was observed as good. The storage capacity of equipment's was fair for all the four states expect Maharashtra (68.0\%). Temperature monitoring practices were found to be either good or fair across all the five states. In Rajasthan, the status of maintenance and repair of cold chain equipment was found to be poor $(30.0 \%)$. Stock management was observed fair for all the five states. In Maharashtra, vaccine distribution was average (59.0\%) and in rest of the states, it was observed fair. Vaccine management practice was good in Bihar (92.0 \%) and fair for other states. Immunization waste management practices was observed average across all the states. The supervision of CCPs at all levels was found to be poor for Bihar (42.0\%) and Uttar Pradesh (35.0\%) (Table 3).

There was poor availability of tally sheets, MPR and HMIS reports in Madhya Pradesh (22.0 \%) and Maharashtra (29.0 \%). Completeness of records was fair for Bihar, Madhya Pradesh, Maharashtra and Uttar Pradesh. In Rajasthan, completeness of records was observed good. Poor consistency of records was observed in Bihar (42.0\%), Madhya Pradesh (36.0 \%) and Maharashtra (24.0\%). Except Uttar Pradesh (66.0\%), the agreement between different recording and reporting formats was found fair for the reviewed states. The status of RCH data entry in the portal was poor in Bihar (9.0\%) and Madhya Pradesh (13.0\%). Use of coverage monitoring chart was only observed in Bihar (75.0 \%) (Table 3).

Poor communication plan was observed in Maharashtra (7.0 \%) and Uttar Pradesh (19.0\%), while in Rajasthan, no communication plan was observed. Advocacy with stakeholders and social mobilization activities were observed poor across the reviewed states. Bridge training was found average in Bihar (50.0\%), Madhya Pradesh (64.0\%) and Maharashtra (56.0\%). In Uttar Pradesh, bridge training was poor, and it not found in Rajasthan. The social media utilization was found to be average in all the states. The media engagement was poor in Maharashtra (46.0\%). In Bihar and Madhya Pradesh, communication activities during monitoring were found fair. Communication activities were found poor in Maharashtra (31.0 \%) and Rajasthan (38.0\%) (Table 3).

Urban Immunization: Urban immunization was assessed in the district headquarters of four reviewed districts and in the state capital. The Governance and accountability were fair in Madhya Pradesh (82.0 $\%)$ and poor in Bihar (47.0\%). Except Bihar, the human resource and infrastructure was found fair in the other states. The status of AEFI reporting and microplanning was found to be poor across all the five states. The equipment status and storage capacity were found fair for the reviewed states, although the equipment maintenance and repair were poor in Uttar Pradesh (43.0 \%). The vaccine distribution practice was found good in Bihar (100.0\%). The vaccine management practices were found average for Maharashtra (63.0\%), Rajasthan (57.0\%) and Uttar Pradesh $(51.0 \%)$. This practice was found fair in Bihar and Madhya Pradesh (Table 3).

The programme implementation was found to be average across all the reviewed states (53.6\%-63.8\%). The vaccine logistic and cold chain mechanism was observed fair across all the states (71.0\%-79.4\%). The mechanism of data recording and reporting was found poor in Madhya Pradesh (36.8\%) and Maharashtra (47.0\%) and average in the remaining three states. The programme communication was found to be poor in all reviewed states, except Madhya Pradesh (62.4\%), and thus needs substantial consideration for improvement. (Fig. 2).

\section{Discussion}

The UIP has delivered excellent result in reducing morbidity and mortality from childhood infections in the last 35 years. ${ }^{13}$ There has been substantial reduction in the incidence of many vaccine preventable diseases, however the success has not been as spectacular as in the developed world and still scope of improvement remains exist. ${ }^{14}$

In spite of all the accomplishments, there are few areas of improvement that needs to be addressed for a better and an improved immunization coverage in the country positive changes, there are still ongoing challenges and shortcoming in the immunization programme. The coverage with vaccines in the National Immunization Programme is suboptimal where only $3 / 5$ th children receive all due vaccines and only 3/4th receive 3 doses of DPT vaccine and situation becomes more complex due to inter-state and intra-state variations in the coverage. ${ }^{15}$ Immunization programme in India has partially succeeded in reducing the burden of vaccine preventable diseases; however, significant proportion of VPDs still exists for the reason of suboptimal coverage with the UIP antigens. ${ }^{16-18}$ In our study, it was observed that the reporting of VPDs was poor in all the five reviewed states. The system for AEFI surveillance is improving but still need to be strengthened. ${ }^{16}$ To streamline the AEFI reporting and management, the AEFI guidelines were revised and widely disseminated in 2015 . The reporting has slightly improved since then and now there is additional focus on conducting causality assessment for serious AEFI. ${ }^{19,20}$ AEFI reporting, microplanning and training status was found to be on adequate in half of the reviewed states. The mechanism of data recording and reporting was found to be unsatisfactory with minimal usage of coverage monitoring charts in four of the five reviewed states which shows that data 
Table 2

The indicators covered under each of the four thematic areas.

\begin{tabular}{|c|c|c|}
\hline Thematic areas of review & Sub-indicators & Measuring indicators \\
\hline \multirow{9}{*}{$\begin{array}{l}\text { Programme } \\
\text { implementation }\end{array}$} & Governance and accountability & Status of review meetings, supportive supervision, coordination with partners. \\
\hline & Human resource and infrastructure & $\begin{array}{l}\text { HR vacancy status for the position of MO-Regular, LHV, ANM-Regular, ANM-Contractual, CCT, ASHA and } \\
\text { AWW. }\end{array}$ \\
\hline & Training & Status of immunization training for Medical Officers, health workers and cold chain handlers. \\
\hline & Microplanning & Availability of micro plans in standardized formats. \\
\hline & Session site observations & $\begin{array}{l}\text { Adherence to micro-plan, headcount survey, due listing and tracking of left outs/dropouts, immunization } \\
\text { safety, supervision, ASHA incentives and Knowledge of ANM. }\end{array}$ \\
\hline & Community assessment & Availability of MCP cards at household level. \\
\hline & Adverse Event Following & Constitution of AEFI committees, availability of blank CRF and AEFI management kit. \\
\hline & Immunization (AEFI) reporting & \\
\hline & Vaccine Preventable Disease reporting & $\begin{array}{l}\text { ANMs knowledge on VPDs and mechanism of weekly VPD data sharing between District Surveillance } \\
\text { Officer and DRCHO office. }\end{array}$ \\
\hline \multirow[t]{9}{*}{$\begin{array}{l}\text { Vaccine logistics and cold } \\
\text { chain }\end{array}$} & Human resource and training & $\begin{array}{l}\text { Availability of Cold Chain Handlers and Vaccine Cold Chain Manager at district/state vaccine store and } \\
\text { cold chain points and their training on VCCH module. }\end{array}$ \\
\hline & Equipment status and storage capacity & $\begin{array}{l}\text { Availability of functional Walk-in freezer, Walk-in cooler, ice-lined refrigerator and deep freezer across } \\
\text { different levels. }\end{array}$ \\
\hline & Temperature monitoring practices & Availability of functional thermometer and assessed temperature logbook. \\
\hline & Equipment maintenance and repair & $\begin{array}{l}\text { Process of preventive maintenance and presence of state committee with trained cold chain technician for } \\
\text { condemnation. }\end{array}$ \\
\hline & Stock management & Review of stock register and matching it with physical stock to assess variation, if any. \\
\hline & Vaccine distribution & $\begin{array}{l}\text { Availability of functional AVD system and vaccine van to ensure uninterrupted vaccine delivery to cold } \\
\text { chain and session site. }\end{array}$ \\
\hline & Vaccine management practices & Availability of job aids, open vial policy, and wastage rate of vaccines. \\
\hline & Immunization waste management & Mechanism of waste disposal and knowledge of CCH about waste disposal. \\
\hline & Supervision of CCP & Supervisory visits made by the officials. \\
\hline \multirow[t]{6}{*}{$\begin{array}{l}\text { Data recording and } \\
\text { reporting system }\end{array}$} & Availability of records & $\begin{array}{l}\text { The availability of due lists at sub center/UPHC, MPR at PHC/CHC, HMIS report (e-copy) and PCTS (e- } \\
\text { copy) for specified six months. }\end{array}$ \\
\hline & Completeness of records & Completeness in the records in MPR and HMIS. \\
\hline & Consistency & Consistency in the records in MPR, PCTS and HMIS report for: OPV1 and OPV3; Penta 1 and Penta 3. \\
\hline & Agreement & $\begin{array}{l}\text { Antigen wise agreement of data between MCP and PCTS, PCTS and HMIS, and RCH registers and MCP } \\
\text { cards. }\end{array}$ \\
\hline & HMIS/PCTS/MCTS portal data entry & The registration of name-based children in the portals. \\
\hline & Coverage monitoring chart & $\begin{array}{l}\text { Availability of coverage monitoring chart to visualize immunization coverages at planning unit/district } \\
\text { HQ. }\end{array}$ \\
\hline \multirow[t]{8}{*}{$\begin{array}{l}\text { Programme } \\
\text { communication }\end{array}$} & Communication planning for RI & $\begin{array}{l}\text { Status of RI communication plan, right from availability of the plans to clarity on role of all stakeholder } \\
\text { involved. }\end{array}$ \\
\hline & Advocacy with stakeholders & $\begin{array}{l}\text { Advocacy with stakeholders (religious leaders, elected leaders, other Government departments, private } \\
\text { practitioners, other NGOs) through review meetings and meetings with community. }\end{array}$ \\
\hline & Social Mobilization activities & $\begin{array}{l}\text { Happening of activities like rallies, street plays, video shows, kiosks during fairs and festivals, display of } \\
\text { banners and posters. }\end{array}$ \\
\hline & BRIDGE training & Details on the BRIDGE training and trainings other than BRIDGE. \\
\hline & Social Media utilization & Use of Facebook, WhatsApp and twitter for RI messages. \\
\hline & Media Engagement & Presence of media spokesperson, their role and information on media workshops. \\
\hline & Communication activities during & Awareness and knowledge levels along with attitude and behavior of community \\
\hline & & $\begin{array}{l}\text { with community leaders and caregivers, information on MAS (in urban areas) to understand their } \\
\text { constitution and involvement in immunization-related mobilization activitie. }\end{array}$ \\
\hline
\end{tabular}

recording and reporting need to be strengthen and use of growth monitoring chart need to be prioritized. However, the completeness of data recording of monthly progress report and health management information system was found to be adequate. In the urban areas, the status of AEFI reporting and microplanning was found to be poor. Whereas vaccine distribution practices and cold chain equipment and storage capacity was found to be good Overall in the review performance in three of the thematic areas were found to be satisfactory and underperformance in programme communication area is really a matter of concern because the effective communication mechanism is core behind success of any public health programme. ${ }^{21}$

These critical gaps in the immunization process as identified in the review were analyzed for each state and Immunization Coverage Improvement plan (ICIP) was prepared. Key parameters of the ICIP includes gaps, corresponding actions, indicators to be tracked from national level, responsibility matrix and timelines for each indicator. The coverage improvement plans, will guide and strengthen the review mechanism of state and district task forces and assess the progress made subsequently help in will achieving the goal of $90 \%$ FIC. For tacking of these indicators, the ICIP, the Immunization Technical Support Unit (ITSU), a technical support to the MoHFW, has developed a web based
ICIP tracking tool. It is expected that the tool will promote competition amongst the states to achieve the indicators and will also support decision making by state based on the progress made by the districts. This tool will also serve to fix accountability of the state to achieve the desired targets. Through this tool, the state governments and partners are required to share status of key indicators on regular basis which will be regularly shared with the progress Immunization division and the reviewed states.

India is known for its multifaceted society and social hierarchy, dealt with higher social, economic, and regional inequality. This needs to be prioritized when developing policies and programs for routine immunization. ${ }^{22}$ There are many factors affecting vaccine implementation and UIP, ranging from over burden of public health systems to beneficent crises, outbreaks, hesitancy and uneven demand for vaccination. This shows a clear need for continued support and strategies in implementation of UIP and sustain the overall gains to achieve the globally agreed immunization targets. Initiatives such as development of ICIP and tracking tools can be adapted in rest of the states which can help states and districts in identification of critical gaps and strengths in the immunization processes. ICIP is anticipated to support Government of India on devising a self-assessment district review checklist and orient 
Table 3

State wise findings of the review.

\begin{tabular}{|c|c|c|c|c|c|}
\hline States & Bihar & Madhya Pradesh & Maharashtra & Rajasthan & Uttar Pradesh \\
\hline \multicolumn{6}{|c|}{ Thematic area 1: Programme implementation (in \%) } \\
\hline Governance and accountability & 79.0 & 63.0 & 57.0 & 54.0 & 57.0 \\
\hline Human resource and infrastructure & 61.0 & 84.0 & 88.0 & 80.0 & 71.0 \\
\hline Training & 84.0 & 35.0 & 60.0 & 71.0 & 43.0 \\
\hline Microplanning & 56.0 & 42.0 & 57.0 & 36.0 & 52.0 \\
\hline Session site observations & 68.0 & 67.0 & 51.0 & 55.0 & 48.0 \\
\hline Community assessment & 68.0 & 65.0 & 56.0 & 66.0 & 64.0 \\
\hline AEFI reporting & 51.0 & 45.0 & 51.0 & 28.0 & 51.0 \\
\hline VPD reporting & 43.0 & 46.0 & 43.0 & 45.0 & 43.0 \\
\hline \multicolumn{6}{|c|}{ Thematic area 2: Vaccine logistics and cold chain (in \%) } \\
\hline Human resource and training & 88.0 & 89.0 & 81.0 & 85.0 & 90.0 \\
\hline Equipment status and storage capacity & 77.0 & 81.0 & 68.0 & 80.0 & 75.0 \\
\hline Temperature monitoring practices & 93.0 & 87.0 & 88.0 & 85.0 & 91.0 \\
\hline Equipment maintenance and repair & 74.0 & 72.0 & 55.0 & 30.0 & 74.0 \\
\hline Stock management & 83.0 & 87.0 & 82.0 & 87.0 & 86.0 \\
\hline Vaccine distribution & 96.0 & 86.0 & 59.0 & 74.0 & 78.0 \\
\hline Vaccine management practices & 92.0 & 74.0 & 82.0 & 86.0 & 81.0 \\
\hline Immunization waste management & 63.0 & 78.0 & 59.0 & 56.0 & 61.0 \\
\hline Supervision of CCP & 42.0 & 61.0 & 65.0 & 67.0 & 35.0 \\
\hline \multicolumn{6}{|c|}{ Thematic area 3: Data recording and reporting system (in \%) } \\
\hline Availability of records & 55.0 & 22.0 & 29.0 & 78.0 & 60.0 \\
\hline Completeness of records & 84.0 & 70.0 & 79.0 & 94.0 & 78.0 \\
\hline Consistency & 42.0 & 36.0 & 24.0 & 56.0 & 58.0 \\
\hline Agreement & 82.0 & 80.0 & 87.0 & 88.0 & 66.0 \\
\hline MCTS/HMIS/PCTS portal data entry & 9.0 & 13.0 & 63.0 & 63.0 & 65.0 \\
\hline Coverage monitoring chart & 75.0 & 0.0 & 0.0 & 0.0 & 0.0 \\
\hline \multicolumn{6}{|c|}{ Thematic area 4: Programme communication (in \%) } \\
\hline Communication planning for RI & 43.0 & 69.0 & 7.0 & 0.0 & 19.0 \\
\hline Advocacy with stakeholders & 29.0 & 40.0 & 23.0 & 34.0 & 29.0 \\
\hline Social Mobilization activities & 25.0 & 44.0 & 36.0 & 21.0 & 27.0 \\
\hline BRIDGE training & 50.0 & 64.0 & 56.0 & 0.0 & 6.0 \\
\hline Social Media utilization & 57.0 & 68.0 & 66.0 & 68.0 & 55.0 \\
\hline Media Engagement & 64.0 & 73.0 & 46.0 & 64.0 & 73.0 \\
\hline Communication activities during monitoring & 77.0 & 79.0 & 31.0 & 38.0 & 56.0 \\
\hline \multicolumn{6}{|c|}{ State wise review findings in the urban areas (in \%) } \\
\hline Governance and accountability & 47.0 & 82.0 & 70.0 & 61.0 & 70.0 \\
\hline Human resource and infrastructure & 44.0 & 74.0 & 78.0 & 78.0 & 77.0 \\
\hline Microplanning & 49.0 & 17.0 & 53.0 & 30.0 & 45.0 \\
\hline Session site observations & 56.0 & 61.0 & 50.0 & 62.0 & 39.0 \\
\hline Community assessment & 69.0 & 65.0 & 56.0 & 69.0 & 62.0 \\
\hline AEFI reporting & 43.0 & 33.0 & 42.0 & 30.0 & 42.0 \\
\hline Equipment status and storage capacity & 89.0 & 83.0 & 70.0 & 84.0 & 93.0 \\
\hline Equipment maintenance and repair & 75.0 & 81.0 & 56.0 & 64.0 & 43.0 \\
\hline Vaccine distribution & 100.0 & 85.0 & 57.0 & 62.0 & 81.0 \\
\hline Vaccine management practices & 71.0 & 81.0 & 63.0 & 57.0 & 51.0 \\
\hline
\end{tabular}

key state officials for district reviews. The states are recommended to conduct district reviews in all districts with $<90 \%$ FIC to identify the gaps in the immunization system and prepare district wise coverage improvement plans. Besides, to increase the immunization coverage, there is a dire need to arrange for health education program sessions for all the parents regarding the importance of complete adherence of vaccination among children. TV, newspaper and other medias can be also promoted as most important sources which can be used for spreading educational messages regarding vaccination.

This kind of review of the UIP at such a large scale has also served as a platform for collaborative efforts to achieve common goals of reaching $90 \%$ FIC in the country. For the partner agencies, the review is a medium to participate in the process to assess the gaps, refine their present strategies to support the program and plan out additional strategies in accordance with the gaps. For the donor, the review process serves as a medium to evaluate the outcomes from their present funded projects and to plan out additional areas through which the identified gaps can be addressed.

To reach each and every one of such a huge cohort is obviously a daunting task. Geographical diversity, cultural diversity and political instability are some problems that are rather unique to India and make the task more complex. Reaching out to mobile/migrant population (that is a significant proportion of population in EAG states) is another challenge which need to be addressed. A Programme like the UIP should be considered not only as a medical intervention but also as a programme requiring effective time bound management which ensures every child gets vaccinated on their due time. The managerial, administrative and governance-related aspects are critical as well as very important component to its success and needs to be further investigated and assessed in a timely manner.

\subsection{Limitations of the study}

The study does not review some of the supply side factor like integration of UIP programme with other maternal and health services. Till now whatever we know that data and management of UIP government side but the role of private sector is missing in our country UIP programme, which is creating gap among the policy holder in quantifying the success of UIP programme. The trend and pattern from NFHS are showing the vaccination from private health facility is increasing, which shows there is dire need to review the private sector engagement in UIP programme. 


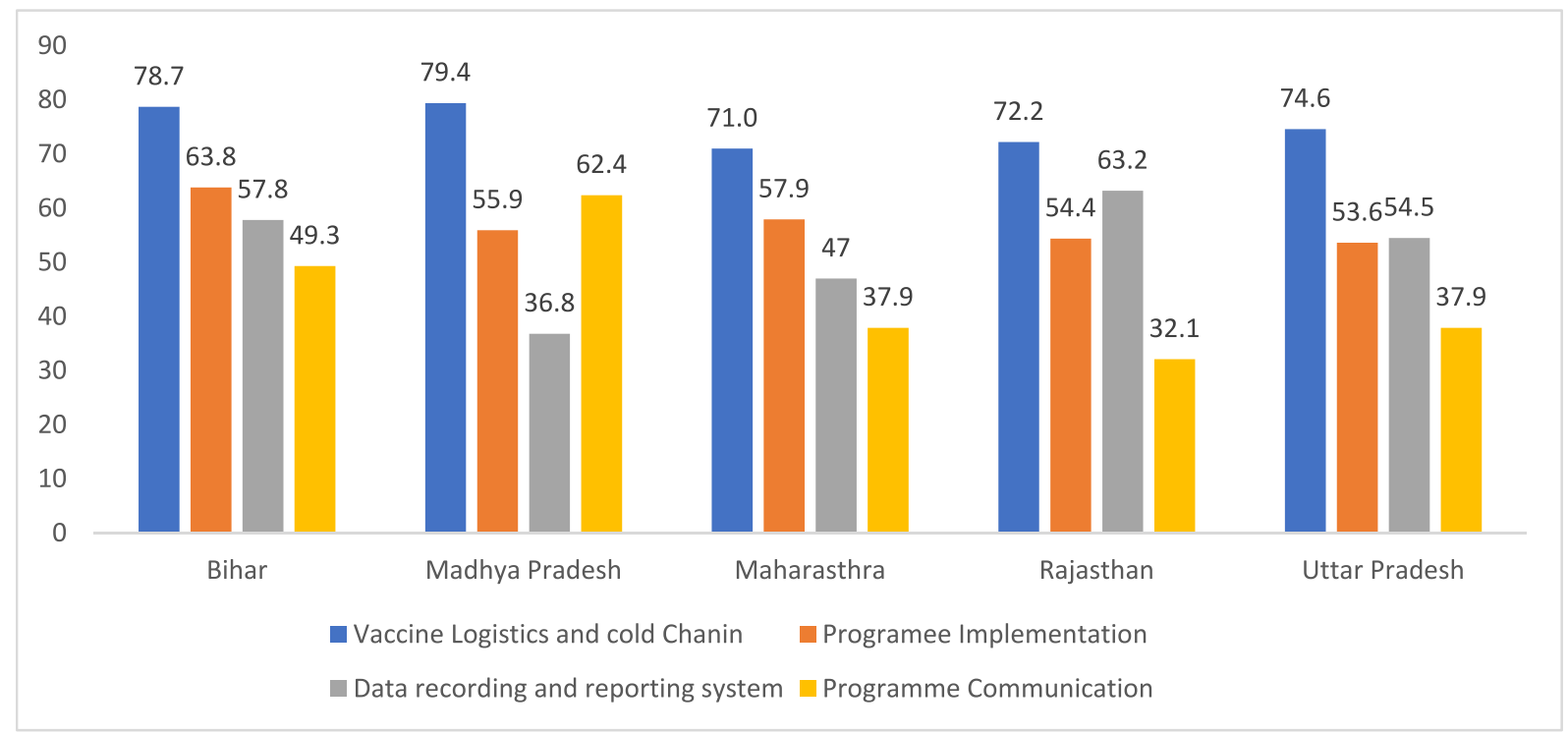

Fig. 2. Thematic area wise assessment of states during review.

\section{Authors contribution}

Conceived and designed the research paper: PD, VG, PH; analyzed the data: PS, GKS; Wrote the manuscript: AA, AR and AK, AR; Refined the manuscript.

\section{Informed consent}

Informed consent was obtained from all individual participants included in the study.

\section{Ethical treatment of experimental subjects (animal and human)}

Disclosure and conflict of Interest has been provided. The study was based on UIP review data from five states which was done by JSI India in collaboration with ministry of health and family welfare (MOHFW)in India with all ethical standards being complied for review. The more information regarding UIP review data can be obtained from doing email on pritu_dhalaria@in.jsi.com.

\section{Declaration of competing interest}

The authors declare that they have no known competing financial interests or personal relationships that could have appeared to influence the work reported in this paper.

\section{Acknowledgments}

The authors would like to thank the participants without whose time and efforts this study would not have been possible.

\section{References}

1 Universal Immunization Programme-National Health Portal.

2 World Health Organization. Strategic Plan 1998-2001. Global Programme for Vaccines and Immunization. 1998. WHO/GPV/98.04.

3 Ministry of Health and Family Welfare, Government of India. Comprehensive Multi Year Plan 2013-2017. New Delhi: MoHFW; 2013.
4 Office of the Registrar General of India. Sample Registration System: Statistical Report 2016. New Delhi: ORGI; 2017.

5 Sissoko D, Trottier H, Malvy D, Johri M. The influence of compositional and contextual factors on non-receipt of basic vaccines among children of 12-23-month old in India: a multilevel analysis. PloS One. 2014;9(9), e106528.

6 Pradhan P, Costa L, Rybski D, Lucht W, Kropp JP. A systematic study of Sustainable Development Goal (SDG) interactions. Earth's Future. 2017;5(11):1169-1179.

7 International Institute for Population Sciences (IIPS) and ICF. National Family Health Survey (NFHS-4), 2015-16: India. Mumbai: IIPS; 2017.

8 Gurnani Vandana, Haldar Pradeep, Aggarwal Mahesh, et al. Improving vaccination coverage in India: lessons from Intensified Mission Indradhanush, a cross-sectoral systems strengthening strategy. BMJ. 2018;363, k4782. https://doi.org/10.1136/ bmj.k4782.

9 New Delhi: MoHFW. Intensified Mission Indradhanush. Coverage evaluation survey, 2018; 2019.

10 Singh Arun. Mission Indradhanush (MI) and intensified mission Indradhanush (IMI): the immunization programmes in India - A Brief Review. 2018:1.

11 Summary of the Approach to Conducting the Intensified Mission Indradhanush (IMI) Case-Study in India. Available in https://pdfs.semanticscholar. org/4465/ff873995cfa921bb136ec95a49b935a 6174d.pdf.

12 Bokonda PL, Ouazzani-Touhami K, Souissi N. Mobile Data Collection Using Open Data Kit. In: International Conference Europe Middle East \& North Africa Information Systems and Technologies to Support Learning. Cham: Springer; 2019, November:543-550.

13 Vashishtha VM, Kumar P. 50 years of immunization in India: progress and future. Indian Pediatr. 2013;50(1):111-118.

14 Srivastava S, Fledderjohann J, Upadhyay AK. Explaining socioeconomic inequalities in immunisation coverage in India: new insights from the fourth National Family Health Survey (2015-16). BMC Pediatr. 2020;20(1):1-12.

15 New Delhi: Government of India and UNICEF. United Nations International Children's Fund. Coverage Evaluation Survey: All India Report 2009. 2010.

16 Government of India. New Delhi: IIPS, Mumbai and ORC Macro and MoHFW. International Institute for Population Studies; 2009. District Level Household Survey (2007-08)- 3.

17 New Delhi: MoHFW; 2012.. Government of India. Comprehensive Multi Year Plan for immunization in India; 2012-2017.

18 New Delhi: CBHI, Ministry of Health and Family Welfare. Central Bureau of health intelligence2011. National Health Profile of India; 2012.

19 Annual reported vaccine preventable disease data. New Delhi. Ministry of health and family welfare, government of India. Central Bureau of Health Intelligence; 2011:1-34.

20 Bernhardt JM. Communication at the core of effective public health. Am J Publ Health. 2004;94(12):2051-2053. https://doi.org/10.2105/ajph.94.12.2051.

21 New Delhi: Ministry of Health and Family Welfare. Govt. Of India. Adverse Events Following Immunization Surveillance and Response Operational Guidelines. 2010, 2010.

22 Chitkara AJ, Thacker N, Vashishtha VM, Bansal CP, Gupta SG. Adverse event following immunization (AEFI) surveillance in India: position paper of Indian academy of pediatrics, 2013. Indian Pediatr. 2013;50(8):739-741. 